\title{
STUDIES OF THE CHANGES OCCURRING IN HEATED SOILS.
}

\author{
By SPENCER UMFREVILLE PICKERING, M.A., F.R.S.
}

IN previous communications ${ }^{1}$ it has been shown that soils heated to temperatures from $60^{\circ}$ to $150^{\circ}$ exhibit an inhibitory effect on the germination of seeds, due to the presence of some toxic substance, which must be a soluble organic, and, probably, nitrogenous, body, for the extent to which germination is retarded is roughly proportional, to both the soluble organic matter and the soluble nitrogen present. That so-called unheated soils, that is, soils which have not been heated above $20^{\circ}-30^{\circ}$, contain some of this substance, was also probable from the fact that the results with unheated and heated soils all lie on continuous curves. It was shown, too, that treatment with antiseptics produced a chemical change in soils, closely similar to that produced by heating them to $60^{\circ}-75^{\circ}$.

As a preliminary step towards obtaining some knowledge of the nature of this deleterious substance, a study was made of the changes which it undergoes when kept under various conditions: and this was preceded by an enquiry as to the trustworthiness of determinations of soil-extracts. Such determinations, if trustworthy, should have an extensive general application in soil analysis, for the soluble organic matter in soils, at any rate, in those of a similar nature, would probably afford a valuable measure of their fertility, and the determination of it wrould be much simpler than that of the nitrogen. From one series of determinations already published ${ }^{2}$, as well as from others which have subsequently been made, it appears that the proportionality between the nitrogen and total organic matter in such extracts is generally very close.

The method adopted consisted of putting 100 grams of soil into a stoppered bottle with 1000 c.c. of water, shaking it up violently once

1 Journ. Agric. Sci. Ir. 411, irr. 33.

2 loc. cit. p. 422. 
every five minutes throughout two hours, leaving it to settle for 15 minutes, and then filtering through paper, an operation which generally occupied 8 to 12 hours. The filtrate was subsequently drawn through a Berkefeld filter, which was thoroughly cleaned by running several portions of the liquid through it first. 750 c.c. of the filtrate were then evaporated to a small bulk in porcelain, and transferred to platinum for evaporation to dryness. The residue, weighed after drying at $100^{\circ}$, and also after the strongest possible ignition over at gas blowpipe, was expressed as a percentage of soil dried at $100^{\circ}$. The preliminary filtering through paper can be dispensed with, though it facilitates the final filtration.

One obvious source of experinental error is the difficulty in weighing a large dish containing the hygroscopic residue. The error in determining the organic matter, which depends on two such weighings, cannot be placed at much less than a possible four milligrams. There are other sources of error which interfere with the absolute value of the results: the water retained after drying at $100^{\circ}$ will be reckoned as so much organic matter, and the apparent weight of this will be further increased by the inorganic residue losing during the ignition any carbon dioxide and chlorides which may be present. On the other hand, volatile organic matter, if present, will be lost during the evaporation, and there may be a mechanical loss in the deflagration of the residue when much nitrate is present.

The compounds in the extracts are, doubtless, numerous, but three distinct features are noticeable. Some extracts, chiefly those of unheated and not very rich soils, leave a yellow granular deposit on evaporation, which, after ignition, is not easily removed by hydrocbloric acid trom the dish. In other cases a dark greasy scum separates before evaporation has proceeded far, and this adheres somewhat tenaciously to the porcelain. This is noticeable chiefly with very rich soils, and also with those which had been kept moist in closed vessels. In a third class, principally with soils heated to $125^{\circ}$ and $150^{\circ}$, no solids separate on concentration, and the residue finally obtained forms a dark glassy mass. On ignition, this, and the residues from some of the less heated soils, especially from those kept moist in closed vessels, leaves an almost black deposit, which, however, contains no carbon, but dissolves readily in hydrochluric acid to form a deep brown solution, which, on heating, or on standing for some hours, becomes colourless or slightly yellow. This is probably due to the presence of manganese. The extracts, those of the last class especially, have a considerable action on platinum, the dish losing about 0.001 gram during each determination. 
TABLE I. Composition of soil extracts obtained under various conditions.

\begin{tabular}{|c|c|c|c|c|c|c|c|c|}
\hline \multicolumn{9}{|c|}{$\begin{array}{l}\text { Time altered. } \\
\text { Organic matter }\end{array}$} \\
\hline \multicolumn{4}{|c|}{ Conditions } & & Per cent. & Relative & Per cent. & Relative \\
\hline $\begin{array}{l}1 . \\
2 . \\
3 . \\
4 . \\
5 . \\
6 . \\
7 . \\
8 . \\
9 .\end{array}$ & $\begin{array}{l}20 \mathrm{mi} \\
40 \\
40 \\
80 \\
120 \\
160 \\
240 \\
320 \\
8 \text { hour }\end{array}$ & $\begin{array}{l}\text { inutes } \\
" \\
" \\
" \\
" \\
" \\
" \\
\text { rs on } 6\end{array}$ & 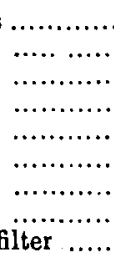 & $\begin{array}{l}\ldots \ldots . . \\
\ldots \ldots . . \\
\ldots \ldots . . \\
\ldots \ldots . . \\
\ldots \ldots . . \\
\ldots \ldots . . \\
\cdots \ldots . . \\
\ldots \ldots . . \\
\ldots \ldots .\end{array}$ & $\begin{array}{l}.0437 \\
.0470 \\
.0372 \\
.0438 \\
.0496 \\
.0410 \\
.0412 \\
.0512 \\
.0431\end{array}$ & $\begin{array}{r}96 \\
102 \\
81 \\
97 \\
108 \\
90 \\
91 \\
112 \\
95\end{array}$ & $\begin{array}{l}\cdot 0345 \\
\cdot 0365 \\
\cdot 0316 \\
\cdot 0400 \\
\cdot 0380 \\
\cdot 0395 \\
\cdot 0370 \\
\cdot 0417 \\
\cdot 0333\end{array}$ & $\begin{array}{r}93 \\
99 \\
86 \\
108 \\
103 \\
107 \\
100 \\
113 \\
90\end{array}$ \\
\hline \multicolumn{9}{|c|}{ Temperature altered. } \\
\hline $\begin{array}{l}5 . \\
10 . \\
11 .\end{array}$ & $\begin{array}{r}6 \cdot 8^{\circ} \\
16 \cdot 7^{\circ} \\
23 \cdot 5^{\circ}\end{array}$ & & & $\begin{array}{l}\ldots \ldots . \\
\cdots \cdots . . \\
\cdots \cdots\end{array}$ & $\begin{array}{l}.0496 \\
.0467 \\
.0519\end{array}$ & $\begin{array}{l}108 \\
102 \\
113\end{array}$ & $\begin{array}{l}.0380^{*} \\
.0427^{*} \\
.0498^{*}\end{array}$ & $\begin{array}{l}103 \\
116 \\
135\end{array}$ \\
\hline \multicolumn{9}{|c|}{ Proportions allered. } \\
\hline $\begin{array}{r}12 . \\
5 . \\
13 .\end{array}$ & $\begin{array}{l}50 \mathrm{gr} \varepsilon \\
100 \\
200\end{array}$ & $\begin{array}{l}\text { ams to } \\
" " \\
" 1\end{array}$ & $\begin{array}{l}\text { o } 1 \text { litre } \\
\text { ", }\end{array}$ & $\begin{array}{l}\ldots \ldots . \\
\ldots \ldots . \\
\ldots \ldots .\end{array}$ & $\begin{array}{l}\cdot 0462 \\
.0496 \\
\cdot 0323^{*}\end{array}$ & $\begin{array}{r}101 \\
108 \\
70\end{array}$ & $\begin{array}{l}.0520^{*} \\
.0380^{*} \\
.0284^{*}\end{array}$ & $\begin{array}{r}141 \\
103 \\
77\end{array}$ \\
\hline Mea. & n, omit & ting th & hose star & ed... & $\cdot 0459$ & 100 & .0369 & 100 \\
\hline
\end{tabular}

The results of the examination of the method of analysis, in which unmanured top soil from Harpenden was used, are collected in Table I, where the relative values entered are those obtained by comparison with the mean given at the bottom of the table. In the first nine entries the proportion used was 100 grams to one litre, at a temperature of $5^{\circ}-10^{\circ}$, the time of digestion being varied from 20 to 320 minutes. As regards both the organic and inorganic matter, no effect whatever is produced by this variation, except a very doubtful increase when the time extended to 320 minutes. In No. 9, the soil was placed on a filter, and the litre of water was drawn through it, this occupying eight hours; but the results are sensibly the same as with the other method of procedure.

In the next three experiments the temperature, both of digestion and filtration, was altered, the proportions being 100 grams to the litre, and the time two hours. The organic matter dissolved does not seem to be sensibly affected by a difference of $16^{\circ}$, but the inorganic matter evidently is so, as it increases regularly with rise of temperature.

In the last three experiments the proportion of soil to water was altered. This does not sensibly affect the organic matter till the proportion exceeds 100 grams to the litre; but the amount of inorganic matter is affected, just as it was by temperature.

It is clear, therefore, that, especially as regards the dissolved organic matter, which is the point of chief importance, the method 
gives perfectly satisfactory results, and these are not affected by such minor variations in the conditions as are likely to occur in practice. The variation of the results lead to a probable error of a single determination of the organic matter being 0.0028 per cent., equivalent to about 002 gram, with the quantities taken, which is not greater than the probable weighing error.

In the investigations of the changes occurring in soils after being heated, the heating of the soil (which was Harpenden soil) was performed, as in former experiments, in closed vessels, two hours at the selected temperatures being allowed. The water present in the soil was 8.8 per cent., calculated on the sample after drying at $100^{\circ}$, its total water capacity being 33 per cent., or 50 parts of water to 100 of dry soil. Portions of 100 grams each of these soils were then kept under two different conditions: in one case, in open glass pans, with water to the saturation point added at intervals as the soil dried up, the soil, also, being broken up occasionally, as would have obtained in ordinary cultivation: in the other case, the soil, with water to the saturation point, was kept in hermetically sealed flasks, which, besides the soil, contained about 15 c.c. of air. In both cases the soil was kept in a table hothouse at about $15^{\circ}$. A few supplementary experiments were made with soil in flasks, kept in the hothouse, but in the dark, and also with soil kept at a winter temperature in the light. No precautions were taken in any case to prevent the reinoculation of the heated soils by bacteria, \&c., but in no cases did any moulds appear on the soils during the experiments.

The water added in all cases was nearly that required for the saturation of the unheated soil, namely, 32 per cent.: but this is rather more than that necessary to saturate the soils which had been heated, for the total water capacity of the heated soils diminishes with the temperature of heating down to 27.4 per cent. for that heated to $150^{\circ}$. Some supplementary experiments, however, showed that the excess which would be present in these cases was without influence on the results: thus, soils which had been heated to $125^{\circ}$ and $150^{\circ}$ respectively, and of which the total water capacity was 30 and 27.4 per cent., respectively, were kept in sealed flasks for 10 days with $32 \cdot 8$ and 25.3 per cent. of water in each case; after which the alteration in the soluble organic matter in them was found to be

With excess of water

With deficit of water

$125^{\circ} \ldots \ldots \ldots+16$ per cent.

$150^{\circ} \ldots \ldots \ldots \ldots+\cdots+9$.

+16 per cent.

+4 " 
Although the heated soils can take up less water than the unheated ones, they retain it with considerably greater firmness. The weight of water added to 100 grams of the various soils in pans, to make up for the evaporation during 16 weeks, ranged from 400 c.c. in the case of the soils heated to below $100^{\circ}$, down to 314 c.c. with those heated to higher temperatures, though the loss did not altogether follow the temperature of heating, owing, no doubt, to irregularities in the air currents in the hothouse.

Sets of the soils were analysed after 10,44 and 112 days, and other sets were used for germination experiments after 44 and 106 days. The original soil taken was also examined by analysis and germination to start with, and again after 119 days, it having been kept during that period in its original air-dried condition in stoppered bottles at a winter temperature. These bottles were capable of holding 30-40 times the quantity of soil present, and they were occasionally opened, so that there was ainple opportunity for oxidation to occur, if any could occur under such conditions.

To ascertain the extent of the accidental variation which might be expected, duplicate experiments were made with soil which had been heated to $60^{\circ}$ and to $125^{\circ}$, both in pans and in sealed flasks. The results were as follows:-

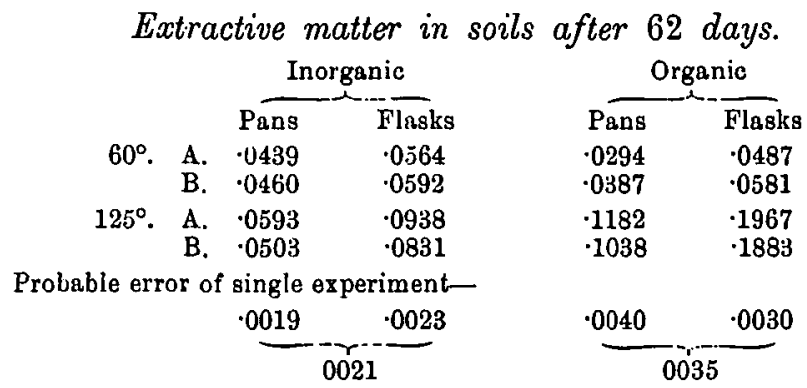

Thus, the probable error as regards the organic matter (.0035), is less than 50 per cent. greater than that determined above as the probable analytical error (0028): as regards the inorganic matter the error is only 0021 . These errors are insignificunt as compared with the total change in composition occurring during the time.

The results of the analyses are contained in Tables II, III and IV, and those of the germination experiments in Table V. In the latter, four sorts of seeds were used, and all the experiments were made in duplicate. The incubation period has alone been considered, the values entered being the average times required for germination, as compared with that required by the same seed in the unheated soil (i.e. heated 
to $30^{\circ}$ ) in the same series. The rye used in the first series had, unfortunately, such a poor germination capacity, that the results with it were of no value.

TABLE II. Soluble matter in soils after being kept watered for various lengths of time in open pans.

\begin{tabular}{|c|c|c|c|c|c|c|c|c|c|c|c|}
\hline \multirow{2}{*}{$\begin{array}{l}\text { After } \\
\text { hent- } \\
\text { ing to }\end{array}$} & \multicolumn{4}{|c|}{ Percentage after } & \multicolumn{3}{|c|}{ P.c. alteration in } & \multicolumn{4}{|c|}{ Relative values after } \\
\hline & $\mathrm{Nil}$ & $10 \mathrm{~d}$. & $44 \mathrm{~d}$ & $112 \mathrm{~d}$. & $10 \mathrm{~d}$ & 44 d. & $112 \mathrm{~d}$. & Nil & $10 \mathrm{~d}$. & $44 \mathrm{~d}$. & $112 \mathrm{~d}$. \\
\hline \multicolumn{12}{|c|}{ Organic matter. } \\
\hline $\begin{array}{r}30^{\circ} \\
60^{\circ} \\
80^{\circ} \\
100^{\circ} \\
125^{\circ} \\
150^{\circ}\end{array}$ & $\begin{array}{l}\cdot 0334 \\
\cdot 0433 \\
\cdot 0684 \\
\cdot 0967 \\
\cdot 1763 \\
\cdot 4187\end{array}$ & $\begin{array}{l}\cdot 0266 \\
.0250 \\
\cdot 0342 \\
\cdot 0705 \\
\cdot 1362 \\
\cdot 2688\end{array}$ & $\begin{array}{l}\cdot 0471 \\
\cdot 0395 \\
\cdot 0498 \\
\cdot 0723 \\
\cdot 1178 \\
\cdot 2333\end{array}$ & $\begin{array}{l}\cdot 0546 \\
\cdot 0349 \\
\cdot 0377 \\
\cdot 0592 \\
\cdot 0727 \\
\cdot 1242\end{array}$ & $\begin{array}{l}-20 \\
-42 \\
-50 \\
-36 \\
-24 \\
-36\end{array}$ & $\begin{array}{l}+41 \\
-9 \\
-27 \\
-25 \\
-33 \\
-44\end{array}$ & $\begin{array}{l}+63 \\
-20 \\
-45 \\
-38 \\
-58 \\
-44\end{array}$ & $\begin{array}{r}100 \\
130 \\
205 \\
289 \\
528 \\
1254\end{array}$ & $\begin{array}{r}100 \\
94 \\
128 \\
265 \\
512 \\
1010\end{array}$ & $\begin{array}{r}100 \\
84 \\
106 \\
153 \\
250 \\
495\end{array}$ & $\begin{array}{r}100 \\
64 \\
69 \\
109 \\
133 \\
227\end{array}$ \\
\hline \multicolumn{12}{|c|}{ Inorganic matter. } \\
\hline $\begin{array}{r}30^{\circ} \\
60^{\circ} \\
80^{\circ} \\
100^{\circ} \\
125^{\circ} \\
150^{\circ}\end{array}$ & $\begin{array}{l}-0390 \\
-0417 \\
0483 \\
\cdot 0.439 \\
0674 \\
\cdot 1125\end{array}$ & $\begin{array}{l}\cdot 0443 \\
0481 \\
.0380 \\
.0434 \\
.0451 \\
.0716\end{array}$ & $\begin{array}{l}\cdot 0633 \\
\cdot 0503 \\
\cdot 0525 \\
\cdot 0509 \\
\cdot 0553 \\
\cdot 0747\end{array}$ & $\begin{array}{l}.0696 \\
.0620 \\
.0530 \\
.0558 \\
\cdot 0495 \\
.0640\end{array}$ & $\begin{array}{l}+14 \\
+15 \\
-21 \\
-1 \\
-33 \\
-61\end{array}$ & $\begin{array}{l}+62 \\
+20 \\
+9 \\
+16 \\
-13 \\
-34\end{array}$ & $\begin{array}{l}+78 \\
+49 \\
+10 \\
+27 \\
-27 \\
-43\end{array}$ & $\begin{array}{l}100 \\
107 \\
124 \\
113 \\
173 \\
288\end{array}$ & $\begin{array}{r}100 \\
109 \\
86 \\
98 \\
102 \\
162\end{array}$ & \begin{tabular}{r|}
100 \\
79 \\
83 \\
80 \\
87 \\
118
\end{tabular} & $\begin{array}{r}100 \\
89 \\
76 \\
80 \\
71 \\
92\end{array}$ \\
\hline
\end{tabular}

TABLE III. Soluble matter in soils after being lept moist for various lengths of time in sealed flasks.

\begin{tabular}{|c|c|c|c|c|c|c|c|c|c|c|c|}
\hline \multirow{2}{*}{$\begin{array}{l}\text { After } \\
\text { hest- } \\
\text { ing to }\end{array}$} & \multicolumn{4}{|c|}{ Percentage after } & \multicolumn{3}{|c|}{ P.c. alterntion in } & \multicolumn{4}{|c|}{ Relative valies after } \\
\hline & $\mathrm{Nil}$ & $10 \mathrm{~d}$. & $43 \mathrm{~d}$. & $116 \mathrm{~d}$. & $10 \mathrm{~d}$. & $43 \mathrm{~d}$. & $116 \mathrm{~d}$. & Nil & $10 \mathrm{~d}$. & $43 \mathrm{~d}$ & $116 \mathrm{~d}$. \\
\hline \multicolumn{12}{|c|}{ Organic matter. } \\
\hline $\begin{array}{r}30^{\circ} \\
60^{\circ} \\
80^{\circ} \\
100^{\circ} \\
125^{\circ} \\
150^{\circ}\end{array}$ & $\begin{array}{l}\cdot 0334 \\
\cdot 0433 \\
\cdot 0684 \\
.0967 \\
\cdot 1763 \\
\cdot 4187\end{array}$ & $\begin{array}{r}0221 \\
.0309 \\
\cdot 0470 \\
.0835 \\
\cdot 1820 \\
\cdot 4238\end{array}$ & $\begin{array}{l}\cdot 0353 \\
.0611 \\
.0721 \\
\cdot 1022 \\
\cdot 1934 \\
\cdot 4751\end{array}$ & $\begin{array}{l}\cdot 0529 \\
\cdot 0834 \\
\cdot 0935 \\
\cdot 1055 \\
\cdot 1904 \\
\cdot 4531\end{array}$ & $\begin{array}{l}-34 \\
-29 \\
-32 \\
-14 \\
+3 \\
+1\end{array}$ & $\begin{array}{l}+6 \\
+41 \\
+5 \\
+6 \\
+10 \\
+13\end{array}$ & $\left|\begin{array}{rr}+ & 59 \\
+ & 93 \\
+ & 37 \\
+ & 9 \\
+ & 8 \\
+ & 8\end{array}\right|$ & $\begin{array}{r}100 \\
130 \\
205 \\
289 \\
528 \\
1254\end{array}$ & $\begin{array}{r}100 \\
140 \\
213 \\
378 \\
824 \\
1918\end{array}$ & $\begin{array}{r}100 \\
173 \\
204 \\
289 \\
548 \\
1346\end{array}$ & $\begin{array}{l}100 \\
158 \\
177 \\
200 \\
360 \\
856\end{array}$ \\
\hline \multicolumn{12}{|c|}{ Inorganic matter. } \\
\hline $\begin{array}{r}30^{\circ} \\
60^{\circ} \\
80^{\circ} \\
100^{\circ} \\
125^{\circ} \\
150^{\circ}\end{array}$ & $\begin{array}{l}\cdot 0390 \\
.0417 \\
\cdot 0483 \\
\cdot 0439 \\
\cdot 0674 \\
\cdot 1125\end{array}$ & $\begin{array}{r}0317 \\
0323 \\
0343 \\
0342 \\
.0372 \\
.0603 \\
.1145\end{array}$ & $\begin{array}{r}0427 \\
\cdot 0560 \\
\cdot 0602 \\
\cdot 0606 \\
.0639 \\
\cdot 1243\end{array}$ & $\begin{array}{l}\cdot 0867 \\
\cdot 0781 \\
\cdot 0740 \\
\cdot 0681 \\
\cdot 0628 \\
\cdot 1551\end{array}$ & $\begin{array}{l}-19 \\
-23 \\
-29 \\
-15 \\
-11 \\
+\quad 2\end{array}$ & $\begin{array}{l}+10 \\
+29 \\
+25 \\
+38 \\
-5 \\
+10\end{array}$ & $\begin{array}{r}+123 \\
+\quad 87 \\
+53 \\
+55 \\
-\quad 7 \\
+\quad 38\end{array}$ & $\begin{array}{l}100 \\
107 \\
124 \\
113 \\
173 \\
288\end{array}$ & $\begin{array}{l}100 \\
102 \\
106 \\
117 \\
190 \\
361\end{array}$ & $\begin{array}{l}100 \\
131 \\
141 \\
142 \\
150 \\
292\end{array}$ & $\begin{array}{r}100 \\
90 \\
85 \\
79 \\
72 \\
179\end{array}$ \\
\hline
\end{tabular}


TABLE IV. Soluble matter in soils kept under various conditions.

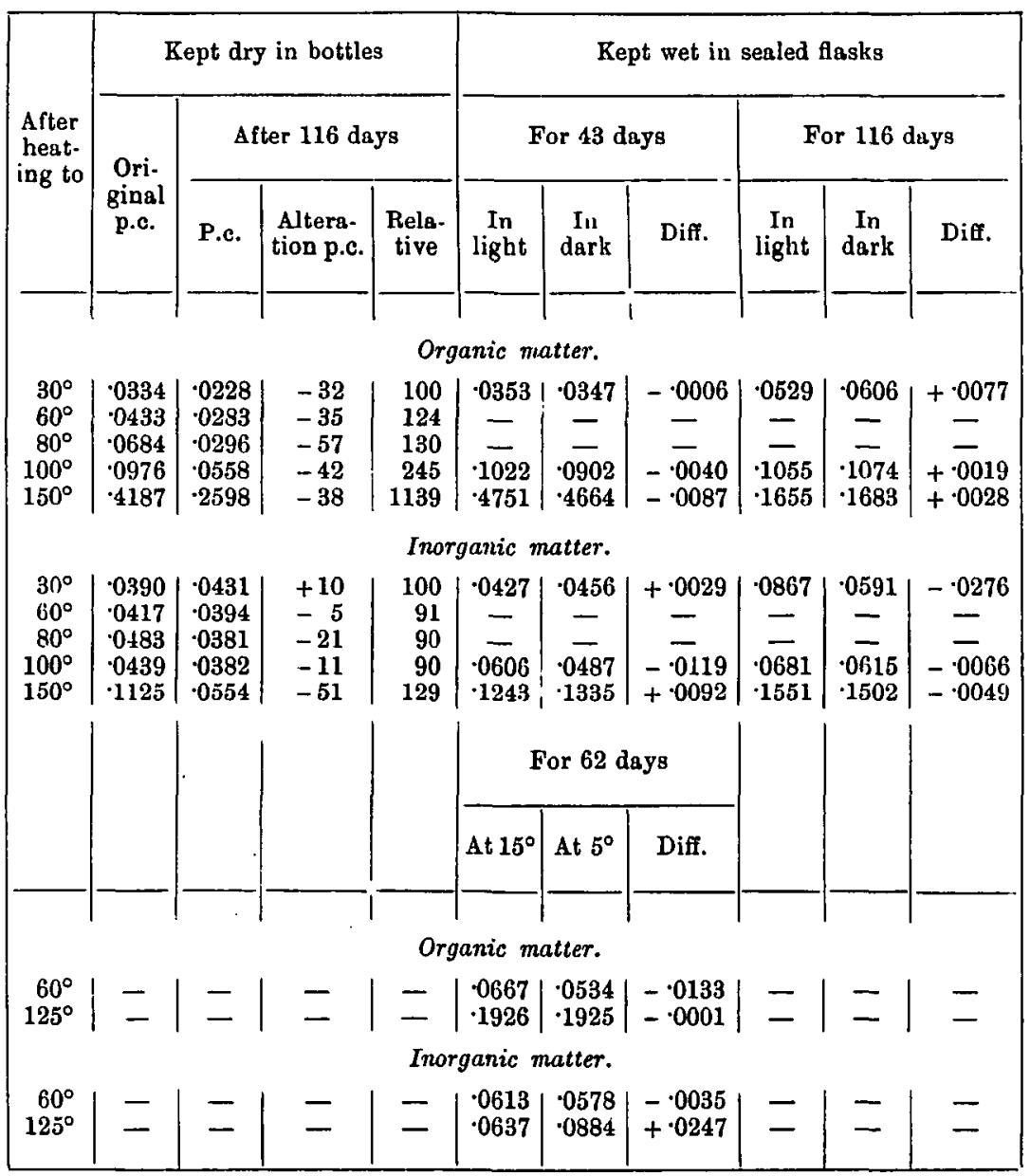


TABLE V. Relative incubation periods of seeds in soils previously heated and kept under various conditions.

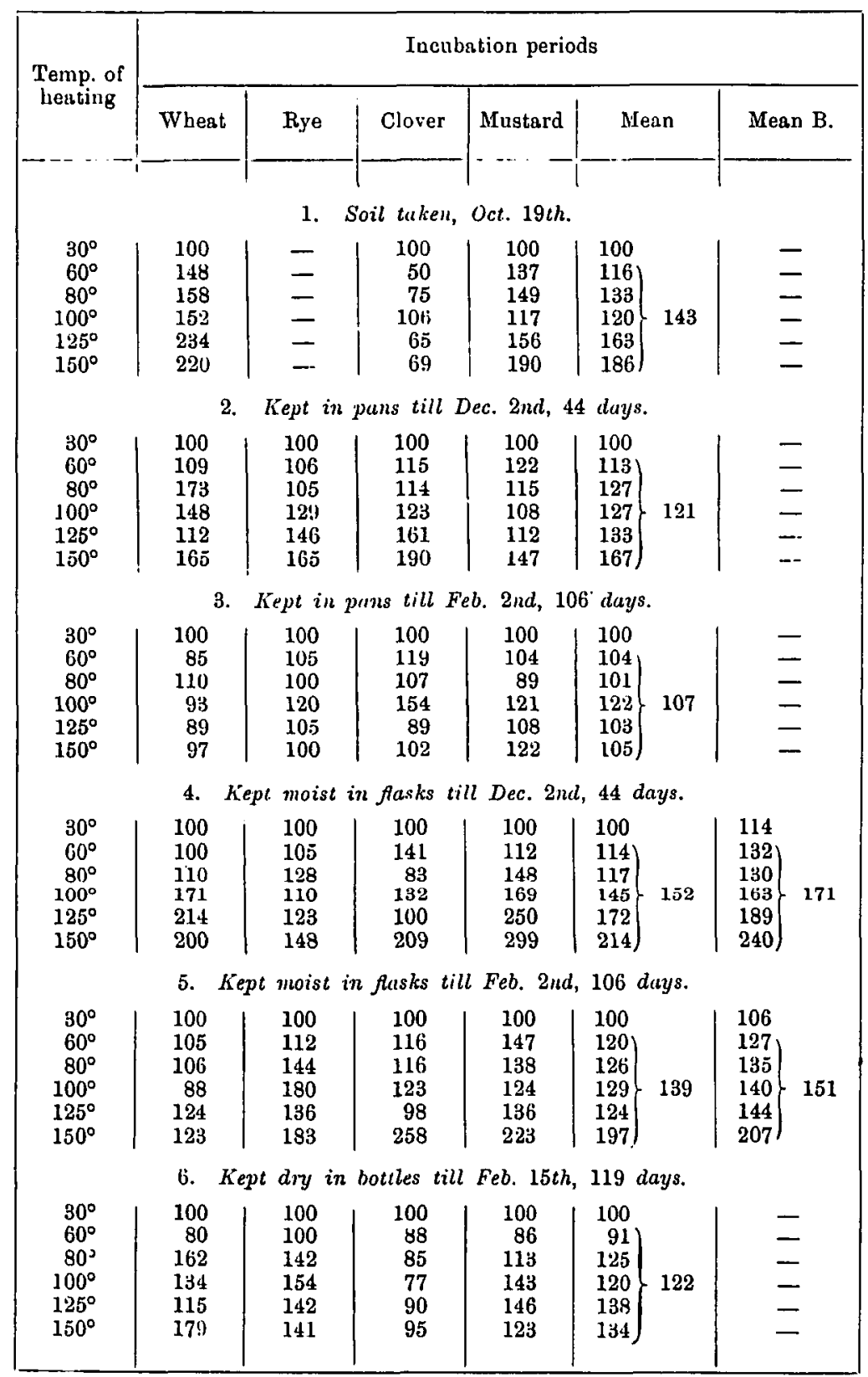


TABLE VI. Results obtained with soils kept moist in sealed flasks compared with those obtained from soils kept in open pans, represented by 100 .

\begin{tabular}{|c|c|c|c|c|c|c|}
\hline \multirow{2}{*}{$\begin{array}{c}\text { After } \\
\text { heating to }\end{array}$} & \multicolumn{3}{|c|}{ Kept for 43-44 day } & \multicolumn{3}{c|}{ Kept for 106-116 days } \\
\cline { 2 - 7 } & Organic & Inorganic & Incubation & Organic & Inorganic & Incubation \\
\hline & & & & & & \\
\hline $30^{\circ}$ & 75 & 68 & 114 & 97 & 124 & 106 \\
$60^{\circ}$ & 155 & 111 & 117 & 242 & 126 & 122 \\
$80^{\circ}$ & 147 & 113 & 102 & 248 & 140 & 134 \\
$100^{\circ}$ & 141 & 119 & 128 & 178 & 122 & 115 \\
$125^{\circ}$ & 164 & 116 & 141 & 262 & 127 & 140 \\
$150^{\circ}$ & 204 & 166 & 144 & 365 & 242 & 197 \\
\hline
\end{tabular}

Charts I and II represent the results of the determinations of soluble organic and inorganic matter, respectively, the cube root of the percentages of the former being taken for plotting, so as to reduce the steepness of the curves. The lettering at the ends of the curves gives the age in days of the soils, as dated from the starting of the experiments. A cursory glance at the figures is sufficient to show that changes of a very marked and complex character occur on keeping the soils, and that the alteration in the amount of soluble matter is sometimes negative and sometimes positive, and may extend to over 100 per cent. of that originally present. There are, however, certain well marked features in these changes. In the first place, the initial curves, marked 0 , are in all cases very regular and simple. Looking at Figs. 1 in each chart, which apply to soils kept watered in open pans, the general result is (with one exception which will be dealt with immediately) that with the unheated, or less highly heated soils, the soluble matter, both organic and inorganic, increases as time passes, but with the more highly heated ones, the soluble matter diminishes, so that the curves representing the results of successive examinations cut each other at some point, this point varying from $50^{\circ}$ to $80^{\circ}$ as regards the organic matter, and from $80^{\circ}$ to $105^{\circ}$ as regards the inorganic matter; that is, soils which have been heated to these temperatures show little or no change in composition on being kept. This result is in full agreement with that of some preliminary experiments which have already been published ${ }^{1}$.

1 Journ. of Agric. Soc. mI. 43. In these the point of intersection was at about $80^{\circ}$. Other determinations were made with a series of soils in which grass was grown for 72 days : the curves in that case were closely similar to those here shown, though not quite so regular, and the point of intersection was $75^{\circ}$. 
With the soils kept in sealed Hasks (Figs. 2 on both Charts), there is a similar, though evidently more complicated, increase in the soluble matter in the case of the less heated soils, but, as regards the highly heated ones, there is no diminution, as in the other case, for the organic matter remains almost constant throughout, or, even increases

Crart I. Soluble organic matter in soils kept.

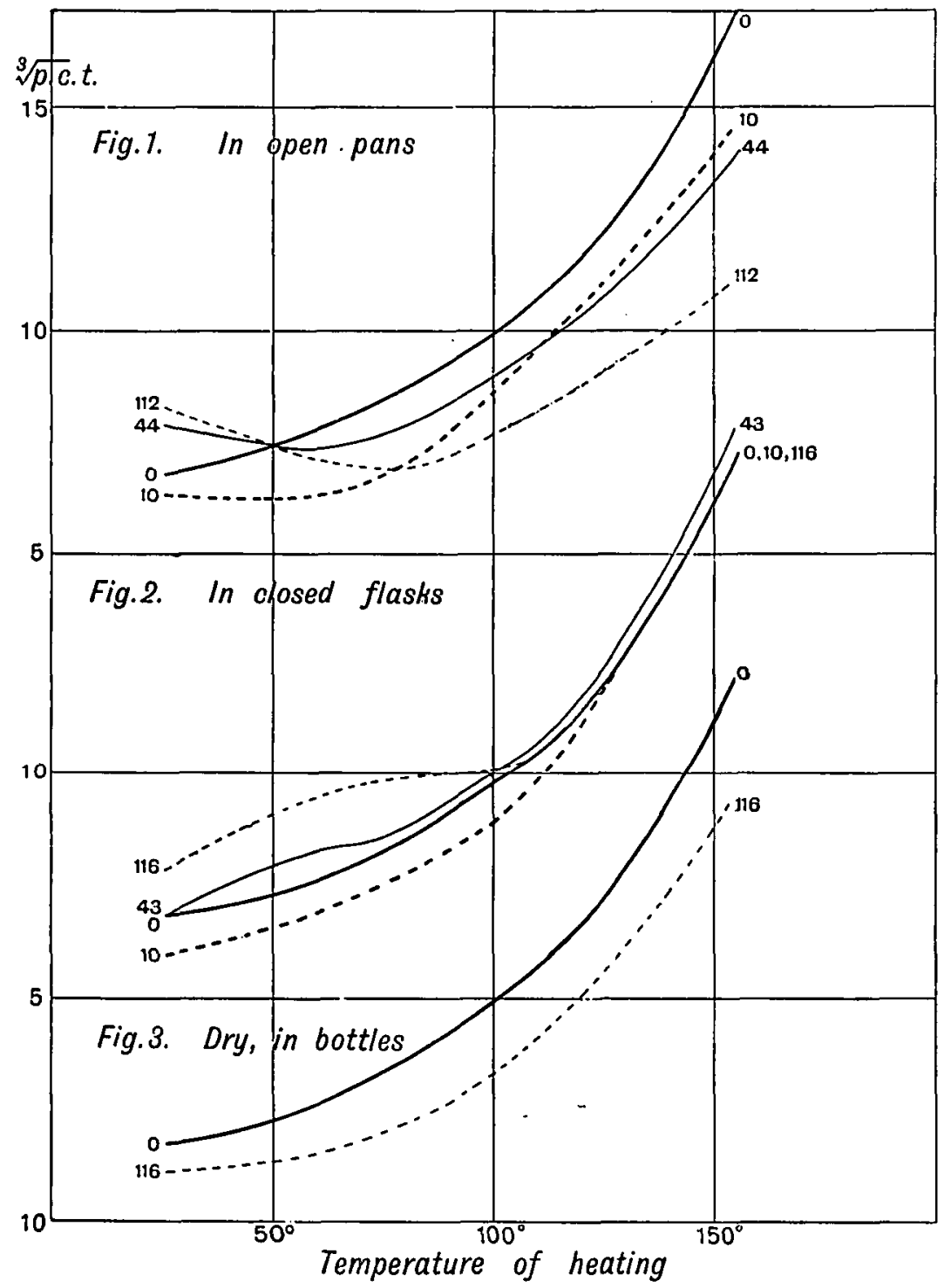


slightly, and the inorganic matter increases too, though only slightly so at first. It is clear, therefore, that the main changes occurring, or the

Chart II. Soluble inorganic matter in soils kept.

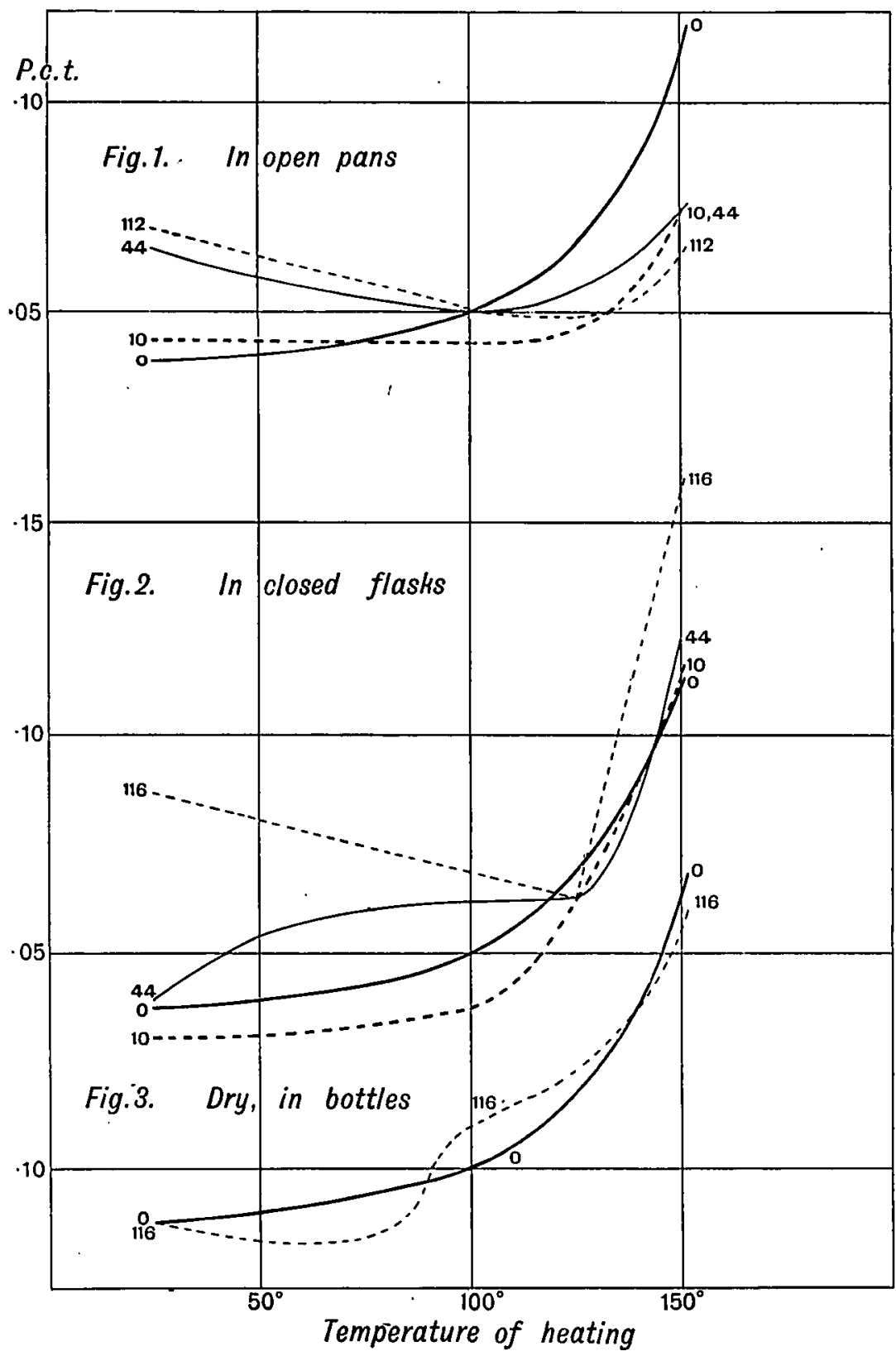


principal substances present, in the highly and less highly heated soils are not identical, and the results strongly indicate that, in these latter, the diminution of the soluble matter is probably due to oxidation, for oxidation would be at a maximum in the open pans, and at a minimum in the sealed flasks. The increase in the soluble matter with the less heated soils does not appear to be influenced in any definite manner by the access or absence of air.

The progress of the changes occurring is, however, not quite so simple, for, the increase in the soluble matter in the less highly heated soils is preceded during the first ten days by a decrease; this is shown equally by Figs. 1 and 2 in Chart I, and Fig. 2 in Chart II, whilst Fig. 1 in Chart II, without showing any such actual reduction, shows an irregularity tending in that direction.

These results indicate that the decrease in the amount of soluble matter is common to all the soils, whatever the temperature of previous heating, but that it is only in the case of the more highly heated ones, which are rich in this oxidisable matter, that the decrease continues throughout any considerable length of time; where less of it is present, as with the less highly heated soils, the supply soon becomes exhausted, and another change, resulting in an increase of soluble matter, becomes predominant. It is probable that this other change, just like the oxidation, occurs equally in all the soils, for it is noticeable that, as regards the inorganic matter, at any rate, an increase eventually asserts itself with the highly heated soils, especially when the conditions are unfavourable for oxidation: the experiments in closed flasks (Fig. 2, Chart II) clearly show this, and there is a tendency in the same direction, even in the experiments in open pans, for the final portions of the curve for 112 days (Fig. 1, Chart II) are high in comparison with those for ten and 44 days.

How far bacterial action may cooperate with atmospheric oxidation in reducing the amount of soluble matter in a heated soil when this is exposed to air is uncertain, but such a reduction does occur in the absence of all bacteria. Three samples of soil were heated in bottles to $127^{\circ}$ : two of these were analysed and found to contain 0.7407 per cent. of soluble organic matter, whilst the third was kept in a very slow stream of dry air, under aseptic conditions, for eight weeks before analysis, and was then found to contain only 0.6478 per cent. The reduction in amount is not large, but the opportunities for oxidation would be very much more limited in this case, than in that of a sample of soil freely exposed to the air, and periodically moistened. 
The soil was found to be perfectly sterile at the conclusion of the experiment.

Whether there would be any decrease in the soluble matter if air was entirely absent, cannot be settled by the present experiments, for the sealed flasks contained some air to start with, but it is most probable that there would be none in such a case.

That oxidation is the cause of the primary decrease in the soluble matter, is further borne out by the results with the dry soil kept in bottles for 116 days (Fig. 3, Charts I, II), where oxidation, though possible, would be less favoured than with soils kept moist. The results with the organic matter show a reduction in the 116 days closely similar to that shown in the other cases after ten days. As regards the inorganic matter (Chart II), the results are of too doubtful a character to afford any evidence in the matter.

That an air-dried soil, on being kept for a few months, should alter in composition, is a fact which the agricultural chemist will have to bear in mind when storing soil-samples. A similar change has been previously noticed in the case of soils treated with antiseptics ${ }^{1}$.

The next step is to compare the results of the analyses with those of the germination of seeds. For this purpose the former must be treated somewhat differently. The absolute values for the incubation periods of seeds can only be compared together in cases where the experiments were made at the same time, for seeds of different ages behave differently: comparative values, taking the incubation period in the unheated soil as a standard, are alone available. The results of the soil analyses expressed in the same way are entered in the last columns of the Tables, and are depicted, together with the germination results, in Charts III and IV. The unlettered curves (....-) in Chart III give the results with the soil kept dry in bottles.

As regards the soils kept in pans (Chart III), it is evident that the diminution in the amount of both soluble organic matter and soluble inorganic matter in the more highly heated soils goes hand in hand with a diminution of their toxic action on the germination of seeds, the three curves for 0,44 and 112 (or 106) days occupying the same relative positions in all cases. The soil kept dry in bottles does not behave in quite so regular a manner, the analyses placing it above the curve 44 , and the germination results, below it.

Whilst it is evident that the soluble matter present in the highly heated soils is toxic towards germination, it would appear that that

1 loc. cit. int. 35. 
which is gradually formed in the less heated soils has no such toxic action: for with soils which have been kept for 44 and 112 days, the curves first dip (diminution of soluble matter) and then rise (increase in soluble matter), whereas the curves for the incubation periods rise

Chart III. Soluble matter in soils kept in pans, and incubation periods.

Relative values.

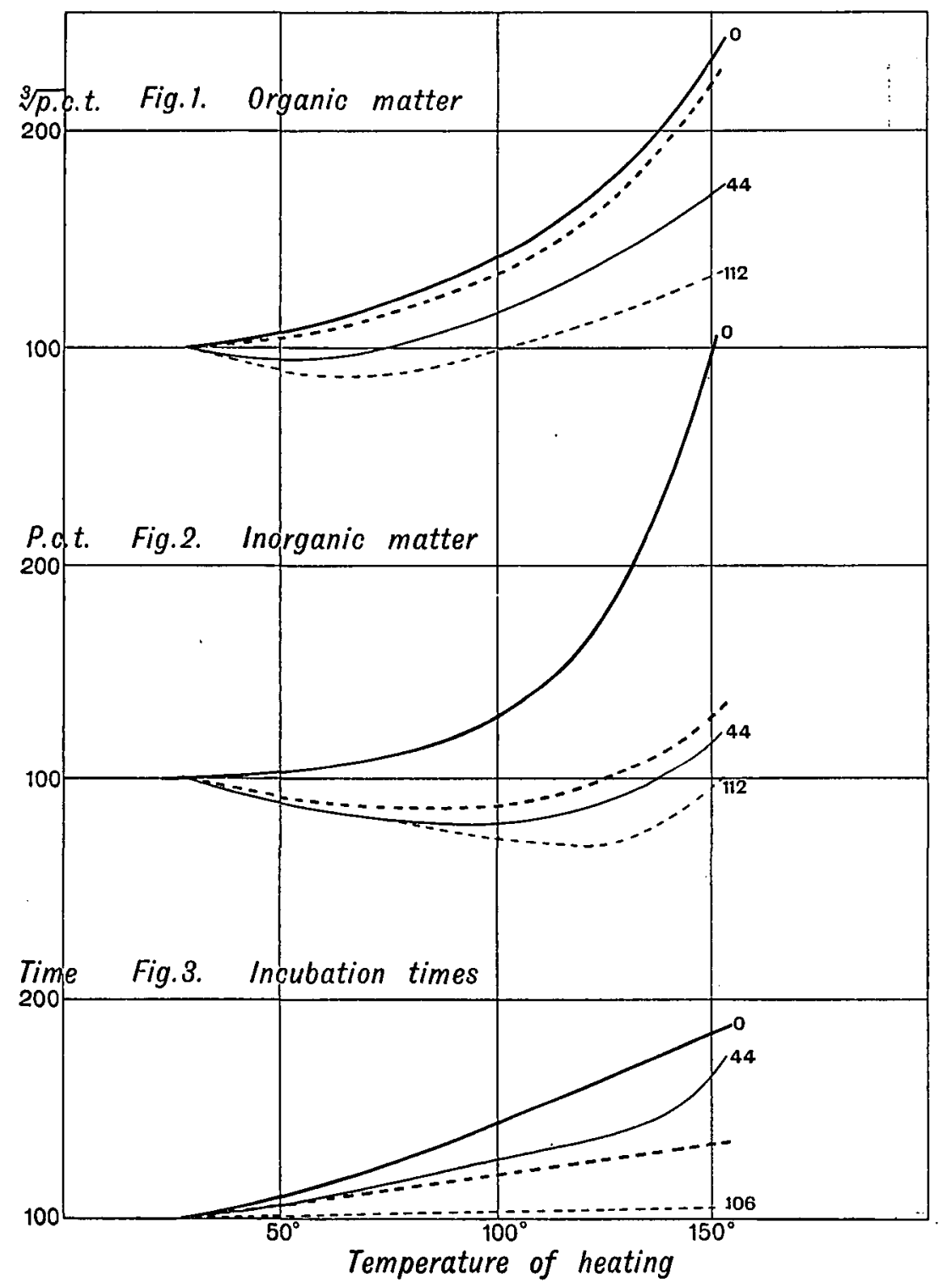


throughout!. This would be seen better by taking the results at $100^{\circ}$ as the standard of comparison; the incubation curves pass in a uniform

Chart IV. Soluble matter in soils kept in flasks, and incubation periods.

Relative values.

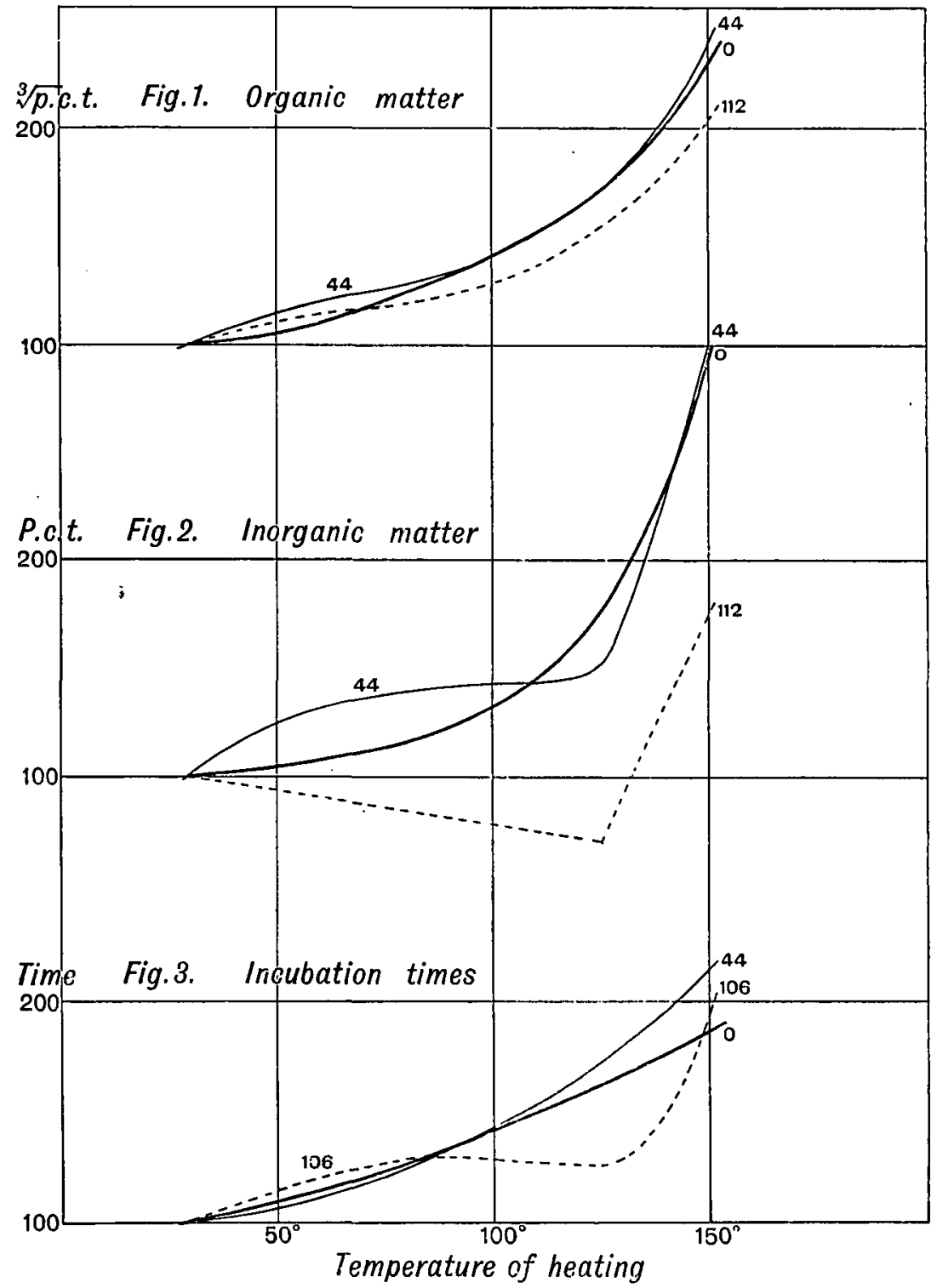

1 This, and various other facts, disprove the suggestions recently made by F. Fletcher (The Cairo Scientific Journal, No. 43, Vol. Iv. April 1910) that delayed germination is due to a decreased rate of inbibition, consequent on the increased amount, and not on the nature, of the soluble matter in the heated soil. 
direction through this point, whereas several of the analysis curves rise on both sides of it.

It is specially noteworthy that the toxic effect of the heated soils has nearly entirely disappeared by the 106th day, the curve (Fig. 3, Chart III) being almost an horizontal line, whereas the soluble matter in the various soils has by no means been reduced to uniformity: evidently the toxic substance is only one of the many substances formed when the soil is heated; it may be destroyed, and yet leave in the soil much of the extra soluble matter formed by the heating.

With the soils kept in closed flasks (Chart IV) there is a similar, though less exact, agreement between the analytical and germination results. The soluble organic matter in the soils heated to the highest temperature (Fig. 1), it is true, shows but little alteration with time, and the incubation periods (Fig. 3) do the same: but the three curves do not occupy quite the same relative position. It must be remembered, however, that the error of the germination results is considerable, and greater concordance could hardly be expected.

The incubation period for the soil heated to $125^{\circ}$ shows a remarkable decrease on long keeping (106 days); and, on comparing this curve with those representing the soluble inorganic matter present (Fig. 2), a striking similarity between them is noticeable, showing that, in this case, the inorganic matter is a potent factor in the germination results.

The germination experiments with the soils kept in open pans and in sealed flasks having been made at the same time, these may be compared together: this has been done in Chart V, the curves "Incubation" being the values for the flasks when those for the pans are represented by a horizontal line at 100 . Corresponding curves for the soluble matter have been drawn in the same way, the values for all of these being given in Table VI. The figures for the more extended period (Fig. 2) are of special interest in showing that it is the soluble matter in the highly heated soils which is the toxic substance, and not that which forms in the less heated soils on keeping, for the great rise in the soluble constituents from $100^{\circ}$ to $150^{\circ}$ is closely reproduced in the rise in the incubation period, whereas the great hump in the curve for the organic matter in the less heated soils produces only a very slight effect on the incubation curve.

1 The germination curves have been smoothed more than the others: the results for soil beated to $100^{\circ}$ lie a good deal off the curves 0 and 106, and, as may be seen from Table V, the values for this soil remained practically constant throughout. 
Whilst the present experiments support in every way the conclusions previously drawn, that the toxic effect on germination is dependent on the increase in the amount of matter rendered soluble by heating the soil, the results do not show that direct proportionality between the increase in the incubation period and the increase in the

Chart V. Behsviour of soil kept in closed flasks compared with that kept in pans represented by 100 .

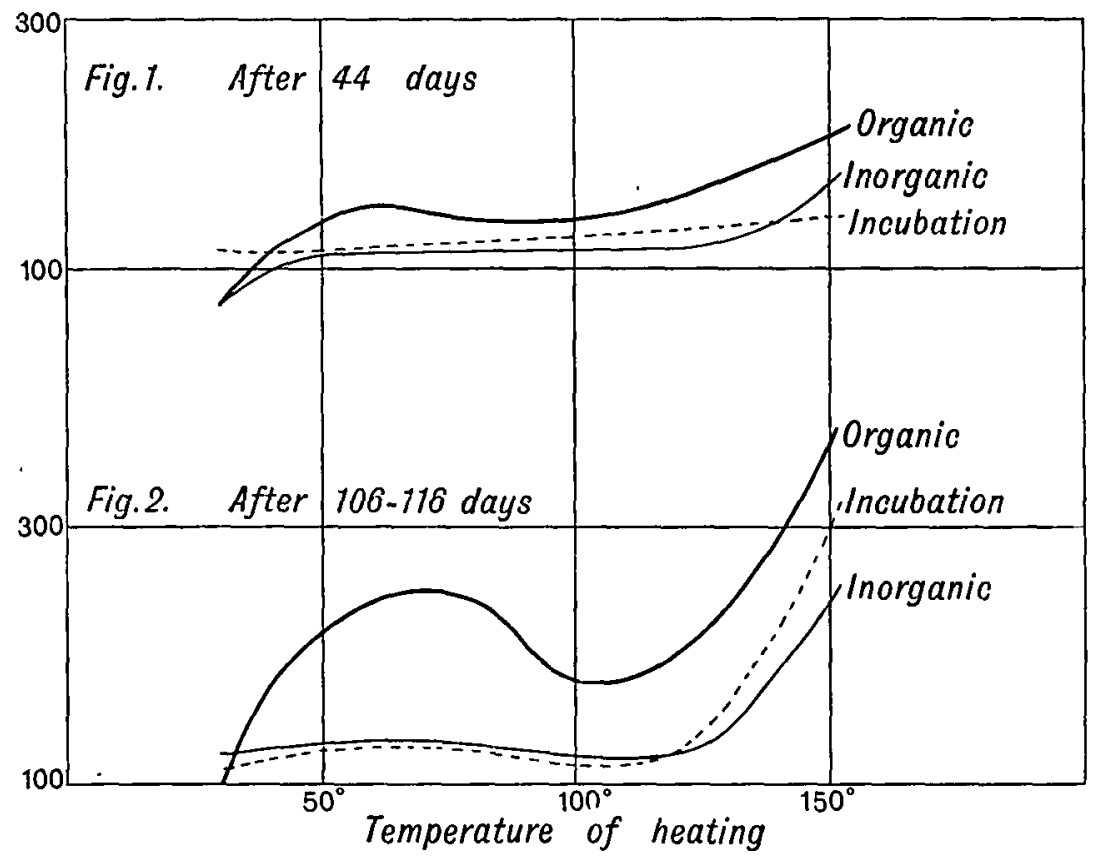

soluble organic matter, which was previously observed. This may well be due to differences in the composition of the soil taken in the two cases, and, as a matter of fact, judging by the extracts, the two soils were very different (cf. Table II above with Table V on p. 422, Vol. Ir). Also, the amount of soluble inorganic matter seems to have a distinct influence on the incubation period in some of the present experiments, as has already been pointed out.

In connection with the most striking curve in Fig. 2, Chart IV, that for 112 days, it may be mentioned that the greasy scum which formed during the evaporation of the extracts in this case, was specially noticeable, both with the least heated and most heated soils, but was nearly absent with the intermediate ones, i.e. from those forming the 
lowest part of the graph. A lesser amount of greasiness was observed with the soils kept in flasks for 44 days, but only with those which had been heated least, and none was observed with these soils when kept for only ten days, nor with any of the soils kept in pans. The greasiness, therefore, is evidently connected with the substances formed gradually by processes other than oxidation.

The effect of light on the changes occurring in soils kept moist in sealed flusks was examined in the experiments quoted in Table IV. The differences in the soluble organic matter are all negative after 43 days, and positive after 116 days: they are probably signiticant, but are too small for useful discussion. The differences in the soluble inorganic matter are mostly larger, but are not regular in character.

Some results with soils kept in closed flasks at an average temperature of $5^{\circ}$, instead of $15^{\circ}$, are entered in the lower part of the table-the values at $15^{\circ}$ for 60 days are obtained by interpolation from the previously quoted results-but do not indicate any certain differences.

To ascertain whether there is any secular variation in the soluble matter in soils, a portion of ground in a cultivated orchard was protected from the weather by a glazed frame placed 18 inches above it, and samples of the soil were examined on about the tenth of each month throughout a year: at the same time some similar soil was kept in basins in an open shed, watered and stirred occasionally, and examined with the other. The results are given in Table VII. With

TABLE VII. Soluble matter in soil on different dates.

\begin{tabular}{|c|c|c|c|c|}
\hline \multirow{2}{*}{ Dute } & \multicolumn{2}{|c|}{ Soil in situ. } & \multicolumn{2}{|c|}{ Soil kept in basins } \\
\hline & Organic & Inorganic & Organic & Inorganic \\
\hline Dec. ...... & .0626 & .0895 & .0626 & .0895 \\
\hline Jan. ........... & .0483 & .0587 & .0665 & .4952 \\
\hline Feb. ...... & .0308 & .0541 & $.05+2$ & $\cdot 1027$ \\
\hline March ... & .0366 & .0490 & .0590 & .0867 \\
\hline April ....... & $\cdot 0417$ & .0618 & - & - \\
\hline May ...... & .0520 & .0470 & .0753 & $\cdot 0844$ \\
\hline June ....... & .0526 & .0579 & .0705 & .0860 \\
\hline July ...... & .0688 & .0749 & .0625 & 0920 \\
\hline August ... & .0744 & $\cdot 0748$ & .0732 & $\cdot 0978$ \\
\hline Sept. ...... & $\cdot 078 y$ & .0820 & - & - \\
\hline Oct. & $\cdot 0576$ & .0736 & $\cdot 0691$ & $\cdot 1028$ \\
\hline Nov. ... & .0690 & $\cdot 1102$ & .0559 & $\cdot 0728$ \\
\hline A vernge... & .0561 & .0695 & .0649 & .0910 \\
\hline
\end{tabular}


the soil in basins there appears to be no variation in any definite direction, whilst, with that left in situ, there is a decrease, both in organic and inorganic matter, throughout the earlier part of the year and an increase subsequently: this, however, may be due merely to the rainfall acting through the exposed soil surrounding the protected patch.

\section{SUMMARY.}

The water extracts obtainable from soils are of constant composition as regards organic matter when the time allowed for the extraction varies from 20 to 320 minutes, the temperature from $7^{\circ}$ to $23^{\circ}$, and the proportions from 5 to 10 of soil to 100 of water. The inorganic matter is not affected by the time, but is by the temperature and proportions.

The increase in soluble matter produced by heating a soil, and the accompanying toxic qualities towards the germination of seeds in it, is gradually reduced by exposing these soils in a moist condition to the air, even under aseptic conditions, but is not reduced, when the soils are kept moist in the absence of air. The destruction of the toxic substance is probably, therefore, due to oxidation.

Unheated soils, or soils heated only to a low temperature, exbibit on keeping an increase in soluble matter; this occurs whether air is admitted or not, and this change, therefore, is probably not an oxidation process: the substance formed, moreover, in such cases appears to have little or no toxic action on germination. This increase of soluble matter, due to the formation of a non-toxic substance, is preceded by a preliminary diminution of soluble matter, precisely similar to the diminution of toxic matter occurring continuously in the more highly heated soils: such toxic matter, therefore, appears to be present in all soils, whether heated or not, though, in the latter case, it is present in such small quantities that it soon becomes completely oxidised.

Air-dried soils, heated and unheated, when kept for some months show an appreciable reduction in soluble constituents, and also in toxic properties.(where such properties were originally present), closely similar to the reduction exhibited by moist soils kept in air for about ten days. 